SYNTHETIC TURF/RECYCLED

TIRE CRUMB RubBer:

Characterization OF THE

BIOLOGICAL ACTIVITY OF

Crumb Rubber IN Vitro

NTP RR 12

JULY 2019 


\section{NTP Research Report on Synthetic Turf/Recycled Tire Crumb Rubber: Characterization of the Biological Activity of Crumb Rubber In Vitro}

Research Report 12

National Toxicology Program

July 2019

National Toxicology Program

Public Health Service

U.S. Department of Health and Human Services

ISSN: 2473-4756

Research Triangle Park, North Carolina, USA 


\section{Table of Contents}

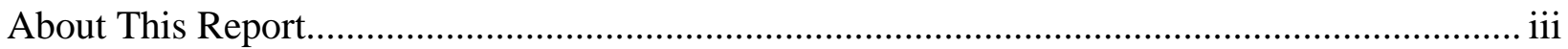

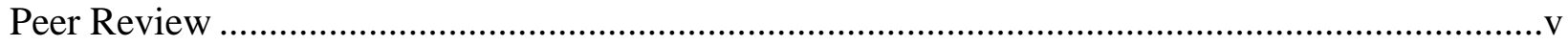

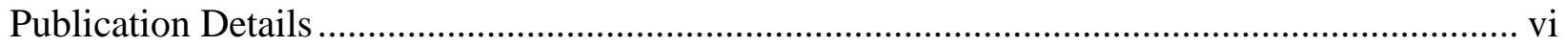

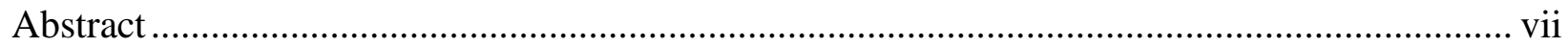

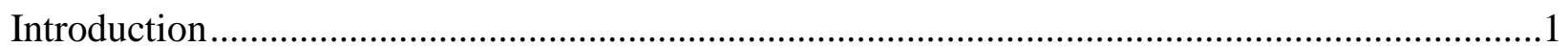

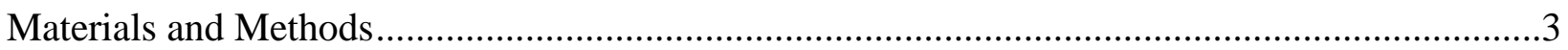

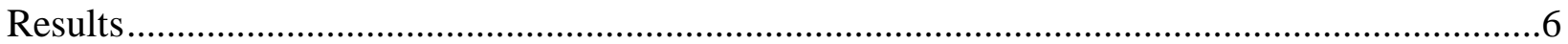

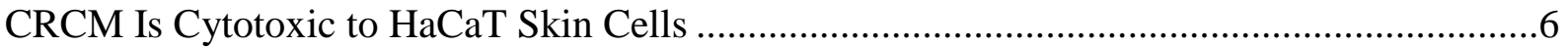

CRCM Is Cytotoxic to HPL-1D Lung Cells .......................................................................6

CRCM Is Cytotoxic to FHs-74-Int Small Intestinal Cells but Not to HepaRG Cells..................7

Crumb Rubber-conditioned PBS and ALF Are Not Cytotoxic to HPL-1D Lung Cells ..............7

UPLC-MS Analysis of CRCM and Crumb Rubber-conditioned PBS or ALF...........................8

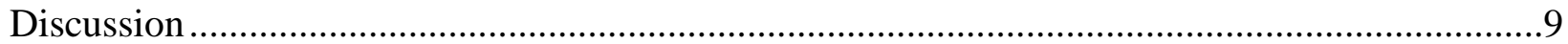

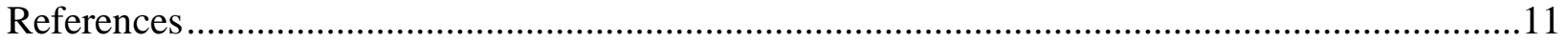

\section{Tables}

Table 1. Chemicals Tentatively Identified in CRCM and Crumb Rubber-conditioned PBS or ALF Using Non-targeted UPLC-MS

Table 2. Peak Areas of Chemicals Tentatively Identified in CRCM and Crumb Rubberconditioned PBS or ALF Using Non-targeted UPLC-MS

\section{Figures}

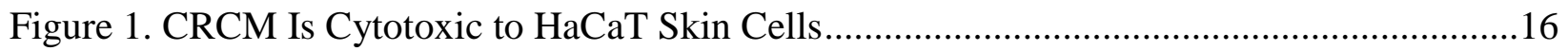

Figure 2. CRCM Is Cytotoxic to HPL-1D Lung Cells ...............................................................17

Figure 3. Histologic Evaluation of HPL-1D Lung Cells Exposed to CRCM ………….................18

Figure 4. CRCM Is Cytotoxic to FHs-74-Int Small Intestinal Cells but Not to HepaRG Cells ....19

Figure 5. Crumb Rubber-conditioned PBS and ALF Are Not Cytotoxic to HPL-1D Lung

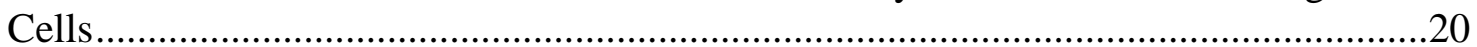

Figure 6. UPLC-MS Analysis of CRCM and Crumb Rubber-conditioned PBS or ALF ..............21

Figure 7. CRCM Is Cytotoxic to HPL-1D Lung Cells Using CTG Assay ......................................22 


\section{About This Report}

National Toxicology Program ${ }^{1}$

${ }^{1}$ Division of the National Toxicology Program, National Institute of Environmental Health

Sciences, Research Triangle Park, North Carolina, USA

\section{Collaborators}

William M. Gwinn, Matthew W. Bell, Erik J. Tokar, Darlene Dixon, David M. Crizer, Nancy C. Urbano, Georgia K. Roberts, Scott A. Masten, Michael J. DeVito

Division of the National Toxicology Program, National Institute of Environmental Health Sciences, Research Triangle Park, North Carolina, USA

Matthew W. Bell, B.S.

David M. Crizer, Ph.D.

Michael J. DeVito, Ph.D.

Darlene Dixon, Ph.D.

William M. Gwinn, Ph.D.

Scott A. Masten, Ph.D.

Georgia K. Roberts, Ph.D.

Erik J. Tokar, Ph.D.

Nancy C. Urbano, B.S.

\section{Contributors}

Division of the National Toxicology Program, National Institute of Environmental Health Sciences, Research Triangle Park, North Carolina, USA

Provided overall programmatic guidance and review

Abee L. Boyles, Ph.D.

John R. Bucher, Ph.D.

Dave E. Malarkey, Ph.D., D.V.M.

Cynthia V. Rider, Ph.D.

Provided oversight of the external peer review

Mary S. Wolfe, Ph.D.

Provided internal peer review

Stephen S. Ferguson, Ph.D.

B. Alex Merrick, Ph.D.

Sreenivasa C. Ramaiahgari, Ph.D.

ICF, Durham, North Carolina, USA

Prepared reports and conducted peer review

David F. Burch, M.E.M., Principal Investigator

Audrey T. Turley, M.S., Program Manager

Susan E. Blaine, B.A.

Natalie K. Blanton, M.P.H.

Tyler W. Cromer, M.P.S. 
Synthetic Turf/Recycled Tire Crumb Rubber:

Characterization of the Biological Activity of Crumb Rubber In Vitro

Lindsey M. Green, M.P.H.

Tara Hamilton, M.S.

Katherine R. Helmick, M.P.H.

Penelope E. Kellar, M.S.

Kimberly C. Osborn, B.S. 


\section{Peer Review}

The draft NTP Research Report on Synthetic Turf/Recycled Tire Crumb Rubber: Characterization of the Biological Activity of Crumb Rubber In Vitro was evaluated by the reviewers listed below. These reviewers served as independent scientists, not as representatives of any institution, company, or governmental agency. In this capacity, reviewers determined if the design and conditions of these NTP studies were appropriate and ensured this NTP Research Report presented the experimental results and conclusions fully and clearly.

\section{Peer Reviewers}

\section{Lawrence Lash, Ph.D.}

Associate Chair, Department of Pharmacology

Wayne State University

Detroit, Michigan, USA

\section{Lawrence Milchak, Ph.D., DABT}

Senior Manager, Corporate Toxicology and Environmental Science

3M Company

St. Paul, Minnesota, USA

\section{Robert Strife, Ph.D.}

Senior Scientist, Consultant (Retired)

Procter \& Gamble, R\&D

West Chester, Ohio, USA 


\section{Publication Details}

Publisher: National Toxicology Program

Publishing Location: Research Triangle Park, NC

ISSN: $2473-4756$

DOI: https://doi.org/10.22427/NTP-RR-12

Report Series: NTP Research Report Series

Report Series Number: 12

Official citation: National Toxicology Program (NTP). 2019. NTP research report on synthetic turf/recycled tire crumb rubber: characterization of the biological activity of crumb rubber in vitro. Research Triangle Park, NC: National Toxicology Program. Research Report 12. 
Synthetic Turf/Recycled Tire Crumb Rubber:

Characterization of the Biological Activity of Crumb Rubber In Vitro

\section{Abstract}

Public health concern for playing on synthetic turf fields with crumb rubber infill has increased in recent years. Crumb rubber manufactured from recycled automobile tires contains potentially toxic and carcinogenic substances, and, with over 12,000 synthetic turf fields in the United States, the potential for exposure is widespread. The National Toxicology Program (NTP) conducted research to improve the understanding of potential human exposure to crumb rubber and its biological activity. The objective of the in vitro studies as described in this report was to determine the cytotoxicity of extracted crumb rubber using cultured human skin-derived keratinocytes (HaCaT cells) and peripheral lung (HPL-1D) cells to reflect potential cellular targets of toxicity from dermal and inhalation routes of exposure, respectively.

Crumb rubber $(100 \mathrm{mg} / \mathrm{mL})$ was incubated in cell type-specific culture medium for 3 hours or 1 , 4 , or 7 days at ambient, $37^{\circ} \mathrm{C}$, or $60^{\circ} \mathrm{C}$ temperatures to allow for the extraction of chemicals from the crumb rubber into the culture medium. Crumb rubber-conditioned medium (CRCM; 1X, generated from $100 \mathrm{mg} / \mathrm{mL}$ crumb rubber) was then sterile-filtered and serially diluted to 0.5 , $0.25,0.125$, and $0.0625 \mathrm{X}$ concentrations for cell exposures. Control medium was simultaneously incubated without crumb rubber at matched times and temperatures. A CRCM-induced decrease in cell viability (i.e., cytotoxicity) was observed for both HaCaT and HPL-1D cell lines after 24hour exposures. For both cell types, cytotoxicity was most pronounced after incubation of crumb rubber at $60^{\circ} \mathrm{C}$, but was also observed at $37^{\circ} \mathrm{C}$ and ambient temperatures. In addition, CRCM was cytotoxic to human small intestinal (FHs-74-Int) cells, which were used to reflect a potential cellular target from ingestion, but not human hepatocytes (HepaRG cells). To determine if the observed cytotoxicity of CRCM was possibly due to the presence of serum proteins in the culture medium during extraction, crumb rubber was incubated in phosphate-buffered saline (PBS) or artificial lung fluid (ALF), sterile-filtered, diluted in culture medium, and then evaluated for cytotoxic effects. ALF, which is similar to pulmonary surfactant, is more physiologically relevant to the lung than the culture medium used for HPL-1D cells. Crumb rubber-conditioned PBS and ALF were much less cytotoxic to the HPL-1D lung cells than CRCM. This suggests that the cytotoxic effect of CRCM in vitro might not be biologically relevant in vivo or to crumb rubber exposures in humans.

Samples of CRCM and crumb rubber-conditioned PBS or ALF were analyzed by non-targeted ultraperformance liquid chromatography-mass spectrometry (UPLC-MS). Principal component analysis of the data showed segregation of chemical features present in the CRCM from the crumb rubber-conditioned PBS and ALF. Chemical compounds associated with the vulcanization of rubber were extracted from the crumb rubber. Among the chemicals identified using non-targeted analysis were 2-mercaptobenzothiazole, N,N'-diphenylguanidine, and 1,2benzisothiazoline-3-one. By providing in vitro data regarding some of the extractable chemical constituents of crumb rubber, in conjunction with chemical characterization and in vivo testing, these studies will contribute to our understanding of potential exposure and biological activity of crumb rubber in humans. 


\section{Introduction}

Synthetic turf fields are widely used in the United States, and their use is expanding. Although such fields historically have been installed in professional sports complexes, they are becoming increasingly popular in community recreational areas, including schools and public parks. These expanded applications include areas across the United States that are used by people of all ages, including young children. In a synthetic turf field, infill materials are spread between the "grass" fibers to provide cushioning and traction. Today, most commonly, the infill consists of granulated rubber pellets referred to as crumb rubber. Crumb rubber is manufactured by shredding used or recycled automobile tires. Recycled tires contain numerous, potentially carcinogenic and toxic substances, either as components of the original tire rubber or accumulated during normal use. While information is known about tire manufacturing, many variables are unknown, including persistence of byproducts, chemical changes during vulcanization, and adsorption of environmental chemicals, which might affect the chemical composition of the ultimate crumb rubber product. A recent literature review of crumb rubber chemical characterization studies outlines some chemicals of concern; using ADMET Predictor $^{\mathrm{TM}}$, this study identified 197 predicted carcinogens, of which 52 have been previously classified as carcinogens by the U.S. Environmental Protection Agency (EPA) or European Chemicals Agency (ECHA) ${ }^{1}$. Other chemicals of concern as well as more information about crumb rubber manufacturing and synthetic turf construction and standards, are described in the 2016 EPA Federal Research Action Plan².

Public concerns about potential health impacts associated with the use of synthetic turf fields have risen dramatically in recent years due to the chemical composition of crumb rubber and the opportunity for widespread, frequent, and long-term exposure, particularly for young athletes. Considering that information to evaluate whether there are adverse health effects from playing on synthetic turf fields is currently limited, several governmental organizations at the international, federal, and state level recently launched research efforts to better understand human exposure and human health hazards focusing on crumb rubber. Internationally, $\mathrm{ECHA}^{3}$ and the National Institute for Public Health and the Environment (RIVM) ${ }^{4}$ of the Netherlands have evaluated the health risks of playing sports on synthetic turf with crumb rubber. The Federal Research Action Plan ${ }^{5-7}$, which involves several U.S. federal agencies, aims to determine and fill important knowledge gaps (FRAP 2016, Appendix B), characterize constituents of recycled tire crumb, and identify ways that people are exposed to tire crumb rubber through typical field use activities. The California Office of Environmental Health Hazard Assessment $(\mathrm{OEHHA})^{8}$ is evaluating exposure scenarios, characterizing new and in-field crumb rubber, and developing biomonitoring protocols.

In 2015, OEHHA nominated synthetic turf/crumb rubber to the National Toxicology Program (NTP) for short-term in vivo and in vitro studies to generate information and improve understanding of potential health impacts of chemicals released from synthetic turf, with an emphasis on crumb rubber. The NTP research program ${ }^{9}$ developed in response to this request used in vitro and in vivo systems to address uncertainties about potential human exposure to hazardous components of crumb rubber. The NTP research approach included both in vivo and in vitro studies and considered the most likely routes of human contact with crumb rubber (e.g., ingestion, dermal contact, and inhalation). The study objective was to investigate which exposure 
conditions could have biological effects, with a focus on characterizing the bioaccessibility and systemic exposure of crumb rubber constituents.

The results of the NTP studies on crumb rubber are communicated in a series of Research Reports ${ }^{10-13}$. The crumb rubber used in the NTP studies was provided by OEHHA specifically for research purposes, and consisted of fresh recycled tire crumb rubber obtained from manufacturing facilities. The physical and chemical characteristics of the material were evaluated using a variety of analytical methods ${ }^{10}$. The characterization work provided an understanding of the material used in the NTP studies and helped interpret chemical analyses in the in vivo and in vitro studies. Characterization of the NTP material will allow interpretation of NTP study findings in relation to crumb rubber evaluated as part of the Federal Research Action Plan (FRAP) and OEHHA research efforts, including samples from new and weathered material, and samples from indoor and outdoor fields. For in vitro testing, multiple cell lines (representing skin, lung, and small intestine) were used to evaluate the extractability of crumb rubber and to look for evidence of biological activity of crumb rubber constituents via measurements of cytotoxicity ${ }^{11}$. For in vivo studies, feasibility testing was conducted to determine what routes of exposure were possible ${ }^{12}$. On the basis of this testing, 14-day in vivo studies were performed ${ }^{13}$ using oral exposure and exposure in bedding. Dermal studies were not conducted on the basis of feasibility work ${ }^{12}$, and feasibility testing for particle and vapor inhalation studies is ongoing.

The objective of this report is to describe the in vitro characterization studies conducted by NTP to evaluate the cytotoxicity of chemicals extracted from crumb rubber using multiple human cell lines to reflect different potential cellular targets of toxicity depending on the route of exposure (dermal, inhalation, or ingestion). By providing in vitro data regarding some of the extractable chemical constituents of crumb rubber, in conjunction with chemical characterization and in vivo testing, these studies will contribute to NTP's understanding of potential exposure and biological activity of crumb rubber in humans. 


\section{Materials and Methods}

Test material. OEHHA provided the crumb rubber used in these studies. The material, manufacture by either an ambient or a cryogenic manufacturing process, was fresh crumb rubber. Three lots were received in multiple 1-L glass jars. First, material from one facility and one type of production process was combined to produce three lots, each weighing approximately $5 \mathrm{~kg}$. Subsequently, all material was combined into one lot (Lot No. CRM06092016). Physical and chemical characterization of this lot is described in other NTP research ${ }^{10}$.

Cell lines and culture media. Human skin-derived keratinocytes (HaCaT cells; American Type Culture Collection (ATCC), Manassas, VA) were cultured in Dulbecco's Modified Eagle (DMEM) medium (Gibco, Gaithersburg, MD) containing 10\% fetal bovine serum (FBS; Gibco) and $1 \%$ antibiotic-antimycotic (Gibco). The HaCaT cell line was generated from primary cultures of normal, adult human keratinocytes ${ }^{14 ; 15}$. Keratinocytes are epithelial cells, which are the predominant cell type in the epidermis (the outermost layer of skin), and thus serve a barrier function. HaCaT cells are immortalized but are not cancer cells (nontumorigenic). These cells retain many features of primary, normal human keratinocytes including morphogenesis, structure, expression of all major cell surface markers, differentiation, and functionality. HaCaT cells have been widely used in vitro in human models of skin injury, inflammation, and repair (e.g., Colombo et al. 2017) ${ }^{16}$.

Human peripheral lung (HPL)-1D cells were kindly provided by Dr. Lucy Anderson (National Cancer Institute, Bethesda, MD) and cultured in Ham's F12 medium (Gibco) containing 1\% FBS (Gibco), $4 \mathrm{mM}$ glutamine (Gibco), penicillin/streptomycin (pen/strep, 100 units per mL/100 $\mu \mathrm{g}$ per mL) (Sigma, St. Louis, MO), 15 mM HEPES ${ }^{\text {a }}$ (Sigma), $0.1 \mu$ M hydrocortisone (Sigma), $5 \mu \mathrm{g} / \mathrm{mL}$ bovine insulin (Sigma), $5 \mu \mathrm{g} / \mathrm{mL}$ human transferrin (Calbiochem, San Diego, CA), and $0.2 \mathrm{nM}$ triiodothyronine (Sigma). The HPL-1D cell line was generated from primary cultures of normal, adult human alveolar epithelial cells ${ }^{17 ; 18}$. These cells are immortalized but are not cancer cells (nontumorigenic). HPL-1D cells exhibit features of type II alveolar epithelial cells (pneumocytes) and retain several characteristics of alveolar epithelial differentiation and responsiveness to growth factors. Type II cells are components of the lower airways (distal lung). Critical functions of type II cells include phagocytosis, production of surfactant, and alveolar repair after injury. HPL-1D cells have been previously used in vitro in human models of metalinduced lung carcinogenesis ${ }^{19 ; 20}$.

FHs-74-Int cells (ATCC) were cultured in Hybri-Care medium (ATCC) containing 10\% FBS (Gibco) and $30 \mathrm{ng} / \mathrm{mL}$ epidermal growth factor (Sino Biological, Beijing, China). The FHS-74Int cell line was generated from primary cultures of normal, fetal human small intestine epithelial cells $^{21 ; 22}$. Small intestine epithelial cells are critical to absorption within the gut. FHs-74-Int cells are finite (not immortalized) and nontumorigenic. These cells have been previously used in vitro as a human small intestine model (e.g., Varughese et al. 2014) ${ }^{23}$.

HepaRG cells (TRL Lonza, Morrisville, NC) were thawed and plated for 24 hours in MHTAP medium followed by culturing for 5 days in MHPIT medium before exposure to CRCM (in

\footnotetext{
a4-(2-Hydroxyethyl)-1-piperazineethanesulfonic acid.
} 
MHPIT medium). MHTAP and MHPIT both contained pen/strep (100 units per mL/100 $\mu \mathrm{g}$ per $\mathrm{mL}$ ) (Sigma). On the basis of the number of cells seeded initially $\left(1 \times 10^{5}\right.$ per well $)$ and the 5 -day culture time before exposure, the HepaRG cells were considered to be differentiated (nonproliferating), adult hepatocyte-like cells intermixed with cholangiocyte-like cells.

All cell types used in these studies were cultured at $37^{\circ} \mathrm{C}$ in $5 \% \mathrm{CO}_{2}$ (100\% humidity).

Crumb rubber incubations and cell exposures. Crumb rubber pellets $(100 \mathrm{mg} / \mathrm{mL})$ were incubated in cell type-specific culture medium $(10 \mathrm{~mL})$ in $15-\mathrm{mL}$ polystyrene conical tubes for 3 hours or 1,4 , or 7 days at ambient, $37^{\circ} \mathrm{C}$, or $60^{\circ} \mathrm{C}$ temperatures (water bath) with vortexing every 1-2 hours during the workday. Control medium was simultaneously incubated without crumb rubber at matched times and temperatures. After centrifugation at $1200 \mathrm{rpm}$ for 5 minutes to spin down the crumb rubber pellets, the crumb rubber-conditioned medium (CRCM; $1 \mathrm{X}$, generated from $100 \mathrm{mg} / \mathrm{mL}$ crumb rubber) was $0.22-\mu \mathrm{m}$ sterile-filtered and serially diluted in (sterile-filtered) control medium to $0.5,0.25,0.125$, and $0.0625 \mathrm{X}$ concentrations for cell exposures. Cells $\left(1 \times 10^{4}\right.$ per well for the HaCaT, HPL-1D, and FHs-74-Int cells) were seeded overnight in 96-well culture plates and then exposed to $100 \mu \mathrm{L} \mathrm{CRCM} \mathrm{(1} \mathrm{to} 0.0625 \mathrm{X}$ ) or control $\left(0 \mathrm{mg} / \mathrm{mL}\right.$ crumb rubber) medium (number of wells $\geq 3$ per experiment) for 24 hours at $37^{\circ} \mathrm{C}$. HepaRG cells $\left(1 \times 10^{5}\right.$ per well $)$ were seeded overnight and then cultured for 5 days prior to exposure. In some experiments, crumb rubber $(100 \mathrm{mg} / \mathrm{mL})$ was also incubated in PBS or ALF for 1 day at $60^{\circ} \mathrm{C}$ for HPL-1D cell exposures. ALF was prepared and provided by Battelle (Columbus, $\mathrm{OH}$ ) according to the method by Pavilonis et al. ${ }^{24}$. PBS (1X) was purchased from ThermoFisher (Waltham, MA). After centrifugation, the crumb rubber-conditioned PBS or ALF was sterile-filtered and diluted with time/temperature-matched culture medium to achieve the following ratios (and associated concentrations): 1:2 (0.5X) and 1:4 (0.25X) for HPL-1D cell exposures. PBS or ALF incubated without crumb rubber for 1 day at $60^{\circ} \mathrm{C}$ was diluted $1: 2$ or 1:4 with culture medium to serve as controls.

Cytotoxicity assays. A cell proliferation (MTS ${ }^{\mathrm{b}}$ ) assay (Promega, Madison, WI) was used to measure cell viability in the 96-well culture plates according to the manufacturer's instructions. Phenazine methosulfate (PMS) was added (1:20) to the MTS tetrazolium salt reagent. After 24 hours of exposure, the culture medium (control or conditioned with crumb rubber) was removed and $100 \mu \mathrm{L}$ of fresh culture medium (not conditioned with crumb rubber) plus $20 \mu \mathrm{L}$ of MTS/PMS (120 $\mu \mathrm{L}$ volume total) was added to the cells, which then were incubated for 2 hours at $37^{\circ} \mathrm{C}$. Metabolically active (viable) cells reduce the MTS into formazan, which is quantified by measuring the absorbance ( $\mathrm{Ab}$ ) at $490 \mathrm{~nm}$ using a plate reader. In separate experiments, $50 \mu \mathrm{L}$ of the fresh culture medium was removed from the wells and $50 \mu \mathrm{L}$ of CellTiter-Glo reagent (Promega) was added to measure cellular adenosine triphosphate (ATP) as an additional measurement of cell viability. Luminescence (relative light units, RLU) was measured after a 3minute incubation using a plate reader.

Preparation of histology slides. In some experiments, HPL-1D cells were cultured on 8-well glass chamber slides and exposed to CRCM (or control medium), as previously described. After exposure, the medium was removed from the chamber slides and the cells were washed with PBS (1X). Upon removal of the PBS, cells were fixed for 10 minutes in $100 \%$ methanol precooled to $-20^{\circ} \mathrm{C}$. Fixed cells were covered with 20X TBS automation wash buffer (Biocare

\footnotetext{
b3-(4,5-dimethylthiazol-2-yl)-5-(3-carboxymethoxyphenyl)-2-(4-sulfophenyl)-2H-tetrazolium, inner salt.
} 
Medical, Pacheco, CA) until staining with hematoxylin and eosin (H\&E) using a Leica ST5020 automated multistainer (Leica Biosystems, Wetzlar, Germany). In this process, the cells were hydrated through a graded ethanol series to distilled water and then stained with H\&E. Cells were next dehydrated through a graded ethanol series and coverslipped using a Leica CV5030 automatic cover slipper (Leica Biosystems).

Ultraperformance liquid chromatography-mass spectrometry. UPLC-MS analysis was performed using a Thermo Vanquish UPLC system with a Thermo Hypersil GOLD aq C18 polar endcapped column $(100 \times 2.1 \mathrm{~mm}, 1.9$-mm particle size $)$ (Thermo Fisher, Waltham, MA) coupled to a Thermo Q Exactive Plus mass spectrometer (Thermo Fisher) with an electrospray ionization (ESI) source. Gradient elution was used for chromatographic separation. The gradient elution method used $0.1 \%$ formic acid in water (mobile phase A) and $0.1 \%$ formic acid in acetonitrile (mobile phase B) with the following gradient elution program: 10-100\% B, 010 minutes; $100 \%$ B, 10-17 minutes; 100-10\% B, 17-19 minutes; and 10\% B, 19-20 minutes. The flow rate was held constant at $0.3 \mathrm{~mL} /$ minutes. Before each run, the column was reequilibrated for 2 minutes with 10\% B. Samples were diluted 1:2 in acetonitrile and run in triplicate. The sample injection volume was $2 \mu \mathrm{L}$. The column temperature was held at ambient temperature, whereas the autosampler tray temperature was set at $4^{\circ} \mathrm{C}$. The mass spectrometer was operated in positive ion mode with a spray voltage of $3.00 \mathrm{kV}$. The S-lens RF level was set at 60 . The capillary and auxiliary gas heater temperatures were set at $300^{\circ}$ and $413^{\circ} \mathrm{C}$, respectively. Sheath gas, auxiliary gas, and sweep gas flow rates were set at 48,11 , and $2 \mathrm{psi}$, respectively. The mass spectrometer was calibrated with positive mode calibration solution (Thermo Fisher). Non-targeted data were acquired using a full scan, data-dependent MS/MS top 10 scan. Full MS scan data were collected at resolution 70,000. MS/MS data were collected at resolution 17,500 with collision energy $30 \mathrm{~V}$. Data were acquired using Thermo Xcalibur 4.0 (Thermo Fisher). Non-targeted data were analyzed with Compound Discoverer 2.1 (Thermo Fisher). This procedure included retention time alignment, peak peaking, integration, and adduct deconvolution. Extracted features were searched against ChemSpider, mzCloud, and KEGG pathway databases. Principal component analysis (PCA) was performed in Compound Discoverer 2.1 to compare chemical features found in the different sample types.

Statistics. One-way or two-way analysis of variance (ANOVA) with Tukey's multiple comparison test was performed where indicated (see figure legends) using GraphPad Prism version 6 software (La Jolla, CA). All data are presented as mean \pm SD with a 2 -sided $p$ value $<0.05$ considered statistically significant. 


\section{Results}

Data for all studies are available in supplemental files in the NTP Chemical Effects in Biological Systems (CEBS) database: https://doi.org/10.22427/NTP-DATA-RR-12.

\section{CRCM Is Cytotoxic to HaCaT Skin Cells}

Crumb rubber was incubated in HaCaT (DMEM-based) medium for 3 hours or 1, 4, or 7 days at ambient, $37^{\circ} \mathrm{C}$, or $60^{\circ} \mathrm{C}$ temperatures, as described in Materials and Methods. For the $60^{\circ} \mathrm{C}$ incubation temperature (Figure 1A), 1 and 0.5X CRCM were cytotoxic (based on decreased $\mathrm{Ab}$ $490 \mathrm{~nm}$ ) to $\mathrm{HaCaT}$ cells at 24 hours for crumb rubber incubation times of 1, 4, and 7 days. Two of the lower concentrations tested, 0.25 and $0.125 \mathrm{X}$ CRCM, were cytotoxic at 24 hours for crumb rubber incubation times of 4 and 7 days. The cytotoxic effects of culture medium conditioned with crumb rubber at $60^{\circ} \mathrm{C}$ were statistically significant compared to HaCaT cells treated with control $(0 \mathrm{mg} / \mathrm{mL}$ crumb rubber $)$ medium.

For the $37^{\circ} \mathrm{C}$ incubation temperature (Figure 1B), 1X CRCM was cytotoxic to HaCaT cells at 24 hours for crumb rubber incubation times of 1, 4, and 7 days. The next lower concentration tested, 0.5X CRCM, was cytotoxic at 24 hours for crumb rubber incubation times of 3 hours, 1 day, and 7 days. The cytotoxic effects of culture medium conditioned with crumb rubber at $37^{\circ} \mathrm{C}$ were statistically significant compared to $\mathrm{HaCaT}$ cells treated with control $(0 \mathrm{mg} / \mathrm{mL}$ crumb rubber) medium.

For the ambient incubation temperature (Figure 1C), 1 and $0.5 \mathrm{X}$ CRCM were cytotoxic to $\mathrm{HaCaT}$ cells at 24 hours but only for the crumb rubber incubation time of 7 days. The cytotoxic effects of culture medium conditioned with crumb rubber at ambient temperature were statistically significant compared to HaCaT cells treated with control $(0 \mathrm{mg} / \mathrm{mL}$ crumb rubber) medium. Similar cytotoxic effects with $\mathrm{HaCaT}$ cells at all crumb rubber incubation temperatures and time durations were observed at 72 hours (https://doi.org/10.22427/NTP-DATA-RR-12). All crumb rubber-conditioned and control media used for HaCaT cell exposures were negative for bacterial and fungal contamination (data not shown).

\section{CRCM Is Cytotoxic to HPL-1D Lung Cells}

Crumb rubber was incubated in HPL-1D (F12-based) medium for 3 hours or 1, 4, or 7 days at ambient, $37^{\circ} \mathrm{C}$, or $60^{\circ} \mathrm{C}$ temperatures, as described in Materials and Methods. For the $60^{\circ} \mathrm{C}$ incubation temperature (Figure 2A), 1, 0.5, and 0.25X CRCM were cytotoxic to HPL-1D cells at 24 hours for all crumb rubber incubation times. The $0.125 \mathrm{X}$ CRCM concentration was cytotoxic at 24 hours for crumb rubber incubation times of 1, 4, and 7 days. The lowest concentration tested, 0.0625X CRCM, was cytotoxic at 24 hours but only for the crumb rubber incubation time of 7 days. The cytotoxic effects of culture medium conditioned with crumb rubber at $60^{\circ} \mathrm{C}$ were statistically significant compared to HPL-1D cells treated with control $(0 \mathrm{mg} / \mathrm{mL}$ crumb rubber) medium. In addition to MTS, the CTG assay, which measures cellular ATP, was used to confirm CRCM-induced cytotoxicity (Figure 7). As shown in Figure 3, the induction of HPL-1D cell death by CRCM was clearly evident histologically on the basis of morphologic changes and cell loss. 
For the $37^{\circ} \mathrm{C}$ incubation temperature (Figure 2B), $1 \mathrm{X} \mathrm{CRCM}$ was cytotoxic to HPL-1D cells at 24 hours for all crumb rubber incubation times. The $0.5 \mathrm{X}$ CRCM concentration was cytotoxic at 24 hours for crumb rubber incubation times of 1,4 , and 7 days. The 0.25 and $0.125 X$ CRCM concentrations were cytotoxic at 24 hours for crumb rubber incubation times of 4 and 7 days. The cytotoxic effects of culture medium conditioned with crumb rubber at $37^{\circ} \mathrm{C}$ were statistically significant compared to HPL-1D cells treated with control $(0 \mathrm{mg} / \mathrm{mL}$ crumb rubber $)$ medium.

For the ambient incubation temperature (Figure 2C), 1X CRCM was cytotoxic to HPL-1D cells at 24 hours for crumb rubber incubation times of 1,4 , and 7 days. The $0.5 \mathrm{X}$ CRCM concentration was cytotoxic at 24 hours for crumb rubber incubation times of 4 and 7 days. The cytotoxic effects of culture medium conditioned with crumb rubber at ambient temperature were statistically significant compared to HPL-1D cells treated with control $(0 \mathrm{mg} / \mathrm{mL}$ crumb rubber $)$ medium. Similar cytotoxic effects with HPL-1D cells (at all crumb rubber incubation temperatures and time durations) were observed at 72 hours (https://doi.org/10.22427/NTPDATA-RR-12). All crumb rubber-conditioned and control media used for HPL-1D cell exposures were negative for microbial (bacterial and fungal) contamination (data not shown).

Under the experimental conditions tested for HaCaT and HPL-1D cells, CRCM was more cytotoxic to HPL-1D cells across the range of exposure concentrations.

\section{CRCM Is Cytotoxic to FHs-74-Int Small Intestinal Cells but Not to HepaRG Cells}

Crumb rubber was incubated in FHs-74-Int (Hybri-Care-based) medium or HepaRG (MHPITbased) medium at $60^{\circ} \mathrm{C}$ for 1 day, as described in Materials and Methods. For these experiments, crumb rubber was incubated at $60^{\circ} \mathrm{C}$ for 1 day because the observed cytotoxicity of CRCM to $\mathrm{HaCaT}$ and HPL-1D cells was most pronounced at the crumb rubber incubation temperature of $60^{\circ} \mathrm{C}$. The 0.5 and $0.25 \mathrm{X}$ CRCM concentrations were cytotoxic to FHs-74-Int cells at 24 hours (Figure 4A), whereas CRCM was not cytotoxic to HepaRG cells (Figure 4B). For the FHs-74-Int small intestinal cells, the cytotoxic effects of culture medium conditioned with crumb rubber at $60^{\circ} \mathrm{C}$ for 1 day were statistically significant compared to cells treated with control $(0 \mathrm{mg} / \mathrm{mL}$ crumb rubber) medium.

\section{Crumb Rubber-conditioned PBS and ALF Are Not Cytotoxic to HPL-1D Lung Cells}

FBS was present in the culture media used for the HaCaT, HPL-1D, and FHs-74-Int cells. To determine if the observed cytotoxicity of CRCM was possibly due to the presence of serum proteins (from FBS) in the culture medium during extraction, crumb rubber was incubated in PBS or ALF at $60^{\circ} \mathrm{C}$ for 1 day and then diluted in culture medium for the HPL-1D lung cell exposures. ALF, which is a biofluid with similarities to pulmonary surfactant, is more physiologically relevant than culture medium to the lung. Whereas 0.5 and $0.25 \mathrm{X} \mathrm{CRCM}$ were observed to be potently cytotoxic to HPL-1D cells at 24 hours (Figure 2A, Figure 3, and Figure 5), the cytotoxicity of crumb rubber-conditioned PBS and ALF was minimal (Figure 5). The cytotoxicity of $0.5 \mathrm{X}$ crumb rubber-conditioned PBS or ALF in culture medium was slight but significantly increased compared to control $(0 \mathrm{mg} / \mathrm{mL}$ crumb rubber) PBS or ALF (1:2 dilution-matched in culture medium), although statistically much less cytotoxic than the CRCM. 


\section{UPLC-MS Analysis of CRCM and Crumb Rubber-conditioned PBS or ALF}

Chemical constituents of the $100 \mathrm{mg} / \mathrm{mL} \mathrm{CRCM}$ and $100 \mathrm{mg} / \mathrm{mL}$ crumb rubber-conditioned PBS or ALF samples were identified via non-targeted UPLC-MS. A PCA plot of the data showed segregation of chemical features present in the CRCM from the crumb rubber-conditioned PBS and ALF (Figure 6). Chemical compounds with a "probable" identification, on the basis of nontargeted analysis, are shown in Table 1 . A "probable" identification ${ }^{25}$ indicated a $>75 \%$ match to the mzCloud database (based on the similarity between experimental and mzCloud library MS/MS spectra), and $>75 \%$ has been reported by others to be a reasonable "cut-off" for nontargeted analyses ${ }^{26}$. Among the chemicals identified using non-targeted analysis, 2-mercaptobenzothiazole (a known rodent carcinogen ${ }^{27}$ ) and two other compounds (N,N'-diphenylguanidine and 1,2-benzisothiazoline-3-one) associated with the vulcanization of rubber were increased in both CRCM and crumb rubber-conditioned PBS compared to respective controls (2-mercaptobenzothiazole was increased 68- and 36-fold in CRCM and PBS, respectively; N,N'-diphenylguanidine was increased 2958- and 8298-fold in CRCM and PBS, respectively; 1,2-benzisothiazolineone was increased 1670- and 2744-fold in CRCM and PBS, respectively). Of these three compounds, only 1,2-benzisothiazoline-3-one was increased (285fold) in crumb rubber-conditioned ALF compared with control ALF. The peak areas of the analytes used to calculate the fold changes are shown in Table 2. 2-Mercaptobenzothiazole, N,N'-diphenylguanidine, and 1,2-benzisothiazoline-3-one had matches to the mzCloud database of 78, 84-85, and 84-89\%, respectively. 


\section{Discussion}

Public health concern about activities on synthetic turf fields with crumb rubber infill has increased in recent years. Crumb rubber manufactured from recycled tires contains potentially toxic and carcinogenic substances. Widespread exposure from the more than 12,000 synthetic turf fields in the United States is possible. NTP conducted in vivo and in vitro research studies to improve the understanding of potential human exposure to crumb rubber and its biological activity. The objective of the in vitro studies as described in this report was to determine the cytotoxicity of extracted crumb rubber using multiple human cell types to reflect different potential cellular targets of toxicity depending on the route of exposure (dermal contact, inhalation, or ingestion). All three of the human cell lines tested (HaCaT, HPL-1D, and FHs-74Int) have been previously used and reported in the literature (see Materials and Methods), and each has been validated as reflective of its respective tissue of origin (skin, lung, and small intestine, respectively).

Crumb rubber pellets could come into contact with exposed skin, or be inhaled or ingested (although, crumb rubber pellets would need to be of a respirable particle size at $<10 \mu \mathrm{m}$ to be inhaled). For these in vitro studies, crumb rubber pellets were incubated in cell type-specific culture medium at different temperatures for different amounts of time to allow for the extraction of chemicals from the pellets into the culture medium to produce crumb rubber-conditioned medium (CRCM). The crumb rubber pellets used in this study were too large for direct exposure of the cultured cells in vitro, thus conditioning of culture medium with the crumb rubber was necessary. CRCM was cytotoxic to multiple human cell lines (HaCaT, HPL-1D, and FHs-74-Int) in vitro that represented different potential cellular targets (skin, lung epithelial, and small intestine epithelial cells, respectively) depending on the route of crumb rubber exposure. The $\mathrm{pH}$ of the culture media used for cell exposures was measured and unaffected by crumb rubber extraction (data not shown). Cytotoxicity was most pronounced after incubation of crumb rubber in culture medium at $60^{\circ} \mathrm{C}$ but also was observed at $37^{\circ} \mathrm{C}$ and ambient temperatures. In contrast to $37^{\circ} \mathrm{C}\left(98.6^{\circ} \mathrm{F}\right), 60^{\circ} \mathrm{C}\left(140^{\circ} \mathrm{F}\right)$ is a non-physiological temperature, but the surface of crumb rubber turf fields has been reported to reach such temperatures ${ }^{28}$. Interestingly, CRCM was not cytotoxic to human HepaRG cells, which might be due to the ability of liver hepatocytes to detoxify chemicals. Hepatocytes were tested because dermal exposure, inhalation, and ingestion can all result in systemic exposures with potential effects on highly perfused liver. An H2AX assay was also used to assess CRCM-induced genotoxicity in HPL-1D cells. At the $0.0625 \mathrm{X}$ concentration, which caused minimal cytoxicity, HPL-1D cells exhibited no increase in $\mathrm{H} 2 \mathrm{AX}$ activity; however, $\mathrm{H} 2 \mathrm{AX}$ activity within cells at concentrations $>0.0625 \mathrm{X}$ was indeterminate due to the high level of cytotoxicity (cell loss) induced by CRCM (data not shown).

The process used in this study to generate CRCM might, in theory, simulate leaching that could occur upon contact of crumb rubber with mucosal secretions lining the skin (sweat), respiratory tract (pulmonary surfactant), or gastrointestinal tract (gastric fluid). However, the intention was to look for evidence of biological activity in vitro via measurements of cytotoxicity and not to necessarily extrapolate in vitro to in vivo biological and toxicological effects. This study did not address the in vitro cytotoxic effects of volatile constituents of crumb rubber, which could be released from crumb rubber upon heating. Volatiles are likely most relevant to crumb rubber exposure via inhalation, due to the large size of crumb rubber pellets, unless fractured crumb 
rubber "dust" of a small enough (respirable) particle size are inhaled and reach the moist surface of the respiratory tract.

It is important, though, to emphasize that the cytotoxic effect observed for CRCM in these in vitro studies might not be biologically relevant in vivo (animal models) or to crumb rubber exposures in humans because crumb rubber-conditioned PBS and biofluid (ALF) were much less cytotoxic than CRCM to HPL-1D cells. ALF, which is a biofluid with similarities to pulmonary surfactant, is more physiologically relevant than culture medium to the lung. Serum proteins (from FBS) present in CRCM, but not in ALF or PBS, might have extracted cytotoxic constituents from the crumb rubber under these experimental conditions. 2-

Mercaptobenzothiazole, N,N'-diphenylguanidine, and 1,2-benzisothiazoline-3-one were extracted from the crumb rubber and tentatively identified in the CRCM via non-targeted analysis. These three chemical compounds are associated with the vulcanization of rubber (benzothiazoles are vulcanization accelerators), but these compounds were also identified in crumb rubber-conditioned PBS (only 1,2-benzisothiazoline-3-one was identified in crumb rubber-conditioned ALF); therefore, they likely did not contribute to the cytotoxic effect of CRCM. In addition, polyethylene glycol (PEG) and polypropylene glycol (PPG) were tentatively identified, which might have been because surfactants can be used in the manufacture of crumb rubber to stiffen and strengthen the rubber ${ }^{29}$. PEGs and PPGs might have contributed to the cytotoxic effect of CRCM; however, this was unlikely because PEGs and PPGs were also present in crumb rubber-conditioned PBS and ALF. Non-targeted analysis (without chemical standards) was performed to quickly provide qualitative data with regards to "what was likely present in the CRCM" as opposed to quantitative data (concentrations of specific chemicals), although peak areas (as shown in Table 2) can be compared across the different analytes. If cytotoxicity had, in fact, been observed after extraction of crumb rubber in PBS and biofluid (ALF), then determination of the specific chemical constituent(s) inducing cytotoxicity would have been warranted. Furthermore, experimental data in vivo ${ }^{13}$ showed little evidence of systemic exposure to chemical constituents of crumb rubber.

Sensitivity to the cytotoxic effects of CRCM could have been attributable to differences in the metabolic activity/capacity between the different cell lines (HPL-1D cells have a relatively longer doubling time compared to $\mathrm{HaCaT}$ cells). Also, FHs-74-Int cells are of fetal origin, which might influence their metabolic capacity, compared to the adult-derived HaCaT and HPL-1D cells. Furthermore, it is not clear as to how the in vitro metabolic activity (sensitivity) of these cell lines reflects their in vivo metabolic activity. All three of these cell lines are primary cellderived, but immortalization likely alters their metabolic activity to some extent. HaCaT and HPL-1D cells are immortalized, but FHs-74-Int cells are not; therefore, the in vitro metabolism of FHs-74-Int cells might better reflect their in vivo metabolic capacity compared to the other two immortalized cell lines. 


\section{References}

1. Perkins AN, Inayat-Hussain SH, Deziel NC, Johnson CH, Ferguson SS, Garcia-Milian R, Thompson DC, Vasiliou V. Evaluation of potential carcinogenicity of organic chemicals in synthetic turf crumb rubber. Environ Res. 2019; 169:163-172.

https://doi.org/10.1016/j.envres.2018.10.018

2. United States Environmental Protection Agency (U.S. EPA). Federal research action plan (FRAP) on recycled tire crumb used on playing fields and playgrounds. 2016. EPA/600/R16/364. https://www.epa.gov/sites/production/files/201612/documents/federal_research_action_plan_on_recycled_tire_crumb_used_on_playing_fields_a nd_playgrounds_status_report.pdf [Accessed: 3 Oct, 2017]

3. European Chemicals Agency (ECHA). Annex XV Report: An evaluation of the possible health risks of recycled rubber granules used as infill in synthetic turf sports fields. 2017. https://echa.europa.eu/documents/10162/13563/annexXV_report_rubber_granules_en.pdf/dbcb4ee6-1c65-af35-7a18-f6ac1ac29fe4

4. Rijksinstituut voor Volksgezondheid en Milieu [Netherlands National Institute for Public Health and the Environment] (RIVM). Evaluation of health risks of playing sports on synthetic turf pitches with rubber granulate. 2017. Report Number: 2017-0016. https://www.rivm.nl/dsresource?objectid=a397bdf3-7aa7-490a-85bd5992b78bcb42\&type $=$ pdf $\&$ disposition $=$ inline

5. United States Environmental Protection Agency (U.S. EPA). Federal research on recycled tire crumb used on playing fields. U.S. Environmental Protection Agency; 2016.

https://www.epa.gov/chemical-research/federal-research-recycled-tire-crumb-used-playing-fields [Accessed: 2017]

6. Agency for Toxic Substances and Disease Registry (ATSDR). Federal research action plan on recycled tire crumb used on playing fields and playgrounds. 2016.

https://www.atsdr.cdc.gov/frap/index.html [Accessed: 2017]

7. Consumer Product Safety Commission (CPSC). Crumb rubber information center. 2016. https://www.cpsc.gov/Safety-Education/Safety-Education-Centers/Crumb-Rubber-SafetyInformation-Center [Accessed: 2017]

8. Office of Environmental Health Hazard Assessment (OEHHA). Synthetic turf studies. 2017. https://oehha.ca.gov/risk-assessment/synthetic-turf-studies [Accessed: 2017]

9. National Toxicology Program (NTP). Synthetic turf/recycled tire crumb rubber. 2018. https://ntp.niehs.nih.gov/results/areas/syntheticturf/index.html [Accessed: 2017]

10. National Toxicology Program (NTP). NTP research report on chemical and physical characterization of crumb rubber. Research Triangle Park, NC: National Toxicology Program; 2019. Research Report 11. https://doi.org/10.22427/NTP-RR-11

11. National Toxicology Program (NTP). NTP research report on synthetic turf/recycled tire crumb rubber: Characterization of the biological activity of crumb rubber in vitro. Research 
Synthetic Turf/Recycled Tire Crumb Rubber:

Characterization of the Biological Activity of Crumb Rubber In Vitro

Triangle Park, NC: National Toxicology Program; 2019. Research Report 12. https://doi.org/10.22427/NTP-RR-12

12. National Toxicology Program (NTP). NTP research report on synthetic turf/recycled tire crumb rubber: Feasibility study in support of non-inhalation in vivo exposures of synthetic turf/recycled tire crumb rubber. Research Triangle Park, NC: National Toxicology Program; 2019. Research Report 13. https://doi.org/10.22427/NTP-RR-13

13. National Toxicology Program (NTP). NTP research report on synthetic turf/recycled tire crumb rubber: 14-day exposure characterization studies of crumb rubber in female mice housed on mixed bedding or dosed via feed or oral gavage. Research Triangle Park, NC: National Toxicology Program; 2019. Research Report 14. https://doi.org/10.22427/NTP-RR-14

14. Boukamp P, Petrussevska R, Breitkreutz D, Hornung J, Markham A, Fusenig N. Normal keratinization in a spontaneously immortalized aneuploid human keratinocyte cell line. J Cell Biol. 1988; 106(3):761-771.

15. Cellosaurus. HaCaT. 2019. Cellosaurus Accession Number: CVCL_0038. https://web.expasy.org/cellosaurus/CVCL_0038 [Accessed: April 15, 2019]

16. Colombo I, Sangiovanni E, Maggio R, Mattozzi C, Zava S, Corbett Y, Fumagalli M, Carlino $\mathrm{C}$, Scaccabarozzi D, Calvieri $\mathrm{S}$ et al. HaCaT cells as a reliable in vitro differentiation model to dissect the inflammatory/repair response of human keratinocytes. Mediators Inflamm. 2017; 2017:7435621. https://doi.org/10.1155/2017/7435621

17. Masuda A, Kondo M, Saito T, Yatabe Y, Kobayashi T, Okamoto M, Suyama M, Takahashi T, Takahashi T. Establishment of human peripheral lung epithelial cell lines (HPL1) retaining differentiated characteristics and responsiveness to epidermal growth factor, hepatocyte growth factor, and transforming growth factor beta1. Cancer Res. 1997; 57(21):4898-4904.

18. Cellosaurus. HPL1D. 2019. Cellosaurus Accession Number: CVCL_8880. https://web.expasy.org/cellosaurus/CVCL_8880 [Accessed: April 15, 2019]

19. Person R, Tokar E, Xu Y, Orihuela R, Ngalame N, Waalkes M. Chronic cadmium exposure in vitro induces cancer cell characteristics in human lung cells. Toxicol Appl Pharmacol. 2013; 273(2):281-288. https://doi.org/10.1016/j.taap.2013.06.013

20. Person R, Ngalame N, Makia N, Bell M, Waalkes M, Tokar E. Chronic inorganic arsenic exposure in vitro induces a cancer cell phenotype in human peripheral lung epithelial cells. Toxicol Appl Pharmacol. 2015; 286(1):36-43. https://doi.org/10.1016/j.taap.2015.03.014

21. Owens R, Smith H, Nelson-Rees W, Springer E. Epithelial cell cultures from normal and cancerous human tissues. J Natl Cancer Inst. 1976; 56(4):843-849.

https://doi.org/10.1093/jnci/56.4.843

22. Cellosaurus. FHs 74 Int. 2019. Cellosaurus Accession Number: CVCL_2899. https://web.expasy.org/cellosaurus/CVCL_2899 [Accessed: April 15, 2019]

23. Varughese E, Bennett-Stamper C, Wymer L, Yadav J. A new in vitro model using small intestinal epithelial cells to enhance infection of Cryptosporidium parvum. J Microbiol Methods. 2014; 106:47-54. https://doi.org/10.1016/j.mimet.2014.07.017 
24. Pavilonis BW, CP; Buckley, B; Lioy, PJ,. Bioaccessibility and risk of exposure to metals and SVOCs in artificial turf field fill materials and fibers. Risk Anal. 2014; 34(1):44-55. http://doi.org/10.1111/risa.12081

25. Schymanski EL, Jeon J, Gulde R, Fenner K, Ruff M, Singer HP, Hollender J. Identifying small molecules via high resolution mass spectrometry: communicating confidence. Environ Sci Technol. 2014; 48(4):2097-2098. https://doi.org/10.1021/es5002105

26. Wang A, Gerona RR, Schwartz JM, Lin T, Sirota M, Morello-Frosch R, Woodruff TJ. A suspect screening method for characterizing multiple chemical exposures among a demographically diverse population of pregnant women in San Francisco. Environ Health Perspect. 2018; 126(7):1-13. https://doi.org/10.1289/ehp2920

27. Q\&A on 2-mercaptobenzothiazole (MBT). Lyon, France: International Agency for Research on Cancer; 2016. https://www.iarc.fr/en/media-centre/iarcnews/pdf/QA\%20on\%20MBT.pdf.

28. Fact sheet: Crumb-rubber infilled synthetic turf athletic fields. New York Department of Health; 2008. https://www.health.ny.gov/environmental/outdoors/synthetic_turf/crumbrubber_infilled/fact_sheet.htm.

29. ECO RUBBER: Crumb recycled rubber as a raw material for new urban furniture products. Interempresas.net; 2011. [accessed April 22, 2019]. 
Synthetic Turf/Recycled Tire Crumb Rubber:

Characterization of the Biological Activity of Crumb Rubber In Vitro

Table 1. Fold Increase Over Control for Chemicals Tentatively Identified in CRCM and Crumb Rubber-conditioned PBS or ALF Using Non-targeted UPLC-MS

\begin{tabular}{|c|c|c|c|c|}
\hline Chemical & $\%$ Match $^{\mathrm{a}}$ & F12 & PBS $^{\mathbf{g}}$ & $\mathbf{A L F}^{\mathrm{h}}$ \\
\hline PEG n12 & $89-94$ & $55^{\mathrm{b}}$ & 68 & 23 \\
\hline PEG n8 & $89-91$ & 125 & 172 & 27 \\
\hline N,N'-Dicyclohexylurea & $89-91$ & 34 & 35 & 14 \\
\hline Atropine & $89-91$ & 11 & 10 & 5 \\
\hline PPG n7 & $87-88$ & 4 & 9 & 4 \\
\hline 1,2-Benzisothiazolin-3-one ${ }^{c}$ & $84-89$ & 1,670 & 2,744 & 285 \\
\hline PEG n7 & $82-90$ & 92 & 177 & 31 \\
\hline Triisopropanolamine & $81-92$ & 71 & 304 & 270 \\
\hline PEG n6 & $79-86$ & 61 & 125 & 19 \\
\hline 9-Oxo-10(E),12(E)-octadecadienoic Acid & $76-79$ & 89 & 112 & 11 \\
\hline PPG n6 & $74-82$ & 43 & 35 & 29 \\
\hline Gelsemine & $72-76$ & 116 & 168 & 63 \\
\hline PEG n11 & $89-93$ & 53 & 60 & $--^{\mathrm{d}}$ \\
\hline PEG n15 & $85-86$ & 63 & 76 & - \\
\hline $\mathbf{N}, N^{\prime}$-Diphenylguanidine ${ }^{c}$ & $84-85$ & 2,958 & 8,298 & - \\
\hline Indole-3-acrylic Acid & 84 & 43 & 69 & - \\
\hline Harmine & 78 & 567 & 548 & - \\
\hline 2-Mercaptobenzothiazole ${ }^{c}$ & 78 & 68 & 36 & - \\
\hline PEG n14 & $76-86$ & 47 & 71 & - \\
\hline N,N'-Diphenylurea & $76-78$ & 13 & 11 & - \\
\hline 15-Deoxy- $\Delta 12,14$-prostaglandin A1 & $76-77$ & 97 & 105 & - \\
\hline PPG n9 & $75-84$ & 10 & 8 & - \\
\hline$\alpha$-Linolenic Acid ${ }^{\mathrm{e}}$ & 89 & 107 & - & - \\
\hline Eicosapentaenoic Acid $^{\mathrm{e}}$ & 79 & 104 & - & - \\
\hline PPG n8 & 83 & - & 12 & - \\
\hline
\end{tabular}

aFragmentation data from MS/MS scan matched to mzCloud database (only those with $>75 \%$ match are shown).

${ }^{\mathrm{b}}$ Fold increase over respective control $=$ (average peak area/average peak area of control).

${ }^{\mathrm{c} A s s o c i a t e d ~ w i t h ~ v u l c a n i z a t i o n ~ o f ~ r u b b e r . ~}$

${ }^{\mathrm{d}}$ Not detected or not increased over respective control.

e Increased only in crumb rubber-conditioned medium (CRCM).

${ }^{\mathrm{f}} \mathrm{F} 12$ is the culture medium used for HPL-1D cells.

gPBS = phosphate-buffered saline.

${ }^{\mathrm{h}} \mathrm{ALF}=$ artificial lung fluid. 
Synthetic Turf/Recycled Tire Crumb Rubber:

Characterization of the Biological Activity of Crumb Rubber In Vitro

Table 2. Peak Areas of Chemicals Tentatively Identified in CRCM and Crumb Rubber-conditioned PBS or ALF Using Non-targeted UPLC-MS

\begin{tabular}{|c|c|c|c|c|c|c|}
\hline Chemical & $\begin{array}{c}\text { Control } \\
\text { F12 }^{\mathrm{e}}\end{array}$ & F12 & $\begin{array}{c}\text { Control } \\
\text { PBS }^{\mathbf{f}}\end{array}$ & PBS & $\begin{array}{c}\text { Control } \\
\text { ALF }^{\mathrm{g}}\end{array}$ & $\mathbf{A L F}$ \\
\hline PEG n12 & $1,967^{\mathrm{a}}$ & 109,035 & 1,796 & 122,441 & 4,201 & 97,115 \\
\hline PEG n8 & 1,902 & 237,295 & 1,341 & 231,099 & 12,500 & 332,920 \\
\hline N,N'-Dicyclohexylurea & 41,751 & $1,405,069$ & 40,666 & $1,425,766$ & 34,825 & 493,927 \\
\hline Atropine & 3,050 & 33,314 & 3,080 & 31,534 & 4,824 & 23,592 \\
\hline PPG n7 & 61,519 & 224,697 & 26,566 & 227,902 & 35,232 & 129,100 \\
\hline 1,2-Benzisothiazolin-3-one $\mathrm{e}^{\mathrm{b}}$ & 904 & $1,509,676$ & 508 & $1,394,667$ & 878 & 250,201 \\
\hline PEG n7 & 2,549 & 234,458 & 1,322 & 234,516 & 10,486 & 321,422 \\
\hline Triisopropanolamine & 21,877 & $1,543,457$ & 9,023 & $2,739,304$ & 4,286 & $1,155,178$ \\
\hline PEG n6 & 3,050 & 185,497 & 1,515 & 188,684 & 13,153 & 248,643 \\
\hline $\begin{array}{l}\text { 9-Oxo-10(E),12(E)- } \\
\text { octadecadienoic Acid }\end{array}$ & 841 & 74,959 & 498 & 55,713 & 2,316 & 24,663 \\
\hline PPG n6 & 4,648 & 199,933 & 5,131 & 178,610 & 5,562 & 162,928 \\
\hline Gelsemine & 388 & 45,163 & 220 & 36,948 & 215 & 13,634 \\
\hline PEG n11 & 2,628 & 140,132 & 2,537 & 152,216 & $-^{c}$ & - \\
\hline PEG n15 & 712 & 45,045 & 633 & 47,782 & - & - \\
\hline N,N'-Diphenylguanidine ${ }^{b}$ & 2,319 & $6,858,862$ & 952 & $7,900,192$ & - & - \\
\hline Indole-3-acrylic Acid & 596 & 25,924 & 416 & 28,873 & - & - \\
\hline Harmine & 3,532 & $2,004,189$ & 3648 & $2,000,510$ & - & - \\
\hline 2-Mercaptobenzothiazole ${ }^{\mathrm{b}}$ & 6,006 & 405,438 & 4,737 & 171,556 & - & - \\
\hline PEG n14 & 1,137 & 53,175 & 848 & 60,472 & - & - \\
\hline N,N'-Diphenylurea & 3,042 & 40,890 & 4,508 & 48,075 & - & - \\
\hline $\begin{array}{l}\text { 15-Deoxy- } \Delta 12,14- \\
\text { prostaglandin } A 1\end{array}$ & 251 & 24,264 & 147 & 15,462 & - & - \\
\hline PPG n9 & 16,918 & 175,321 & 17,478 & 142,037 & - & - \\
\hline$\alpha$-Linolenic Acid ${ }^{\mathrm{d}}$ & 154 & 16,497 & - & - & - & - \\
\hline Eicosapentaenoic Acid $^{\mathrm{d}}$ & 190 & 19,876 & - & - & - & - \\
\hline PPG n8 & - & - & 18,849 & 235,362 & - & - \\
\hline
\end{tabular}

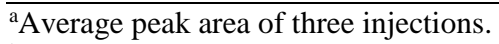

${ }^{\mathrm{b}}$ Associated with vulcanization of rubber.

${ }^{\mathrm{c}}$ Not detected or not increased over respective control.

${ }^{\mathrm{d}}$ Increased only in crumb rubber-conditioned medium (CRCM).

${ }^{\mathrm{e}} \mathrm{F} 12$ is the culture medium used for HPL-1D cells.

fPBS $=$ phosphate-buffered saline.

${ }^{\mathrm{g}} \mathrm{ALF}=$ artificial lung fluid. 

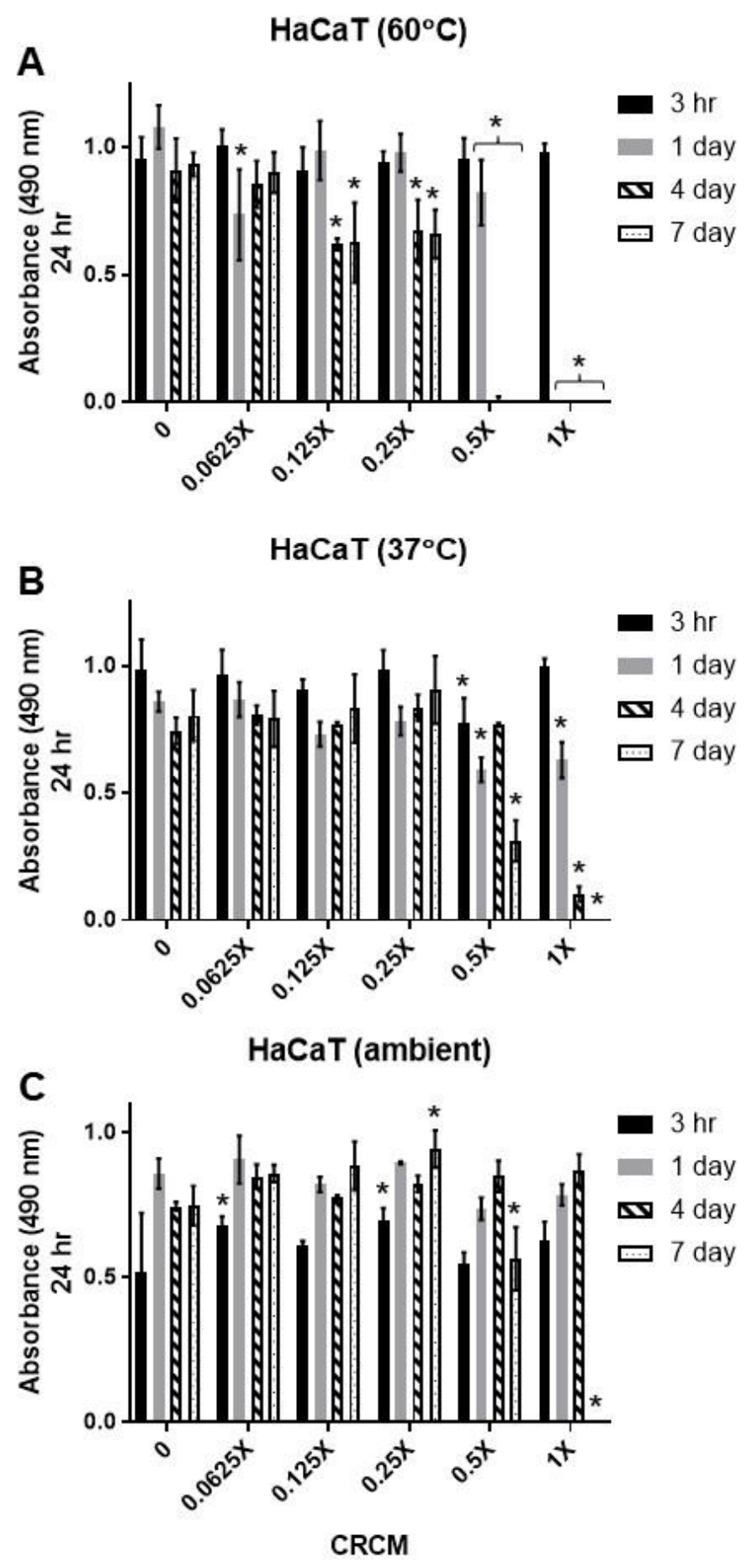

Figure 1. CRCM Is Cytotoxic to HaCaT Skin Cells

HaCaT cells were exposed to crumb rubber-conditioned medium (CRCM) $(1,0.5,0.25,0.125$, or $0.0625 \mathrm{X})$ or control $(0 \mathrm{mg} / \mathrm{mL}$ crumb rubber) medium for 24 hours, as described in Materials and Methods. Cell viability (Ab $490 \mathrm{~nm}$ ) was measured using an MTS assay. Mean \pm SD $(n=3)$ values are shown on graphs (for a single representative experiment). (A) Crumb rubber incubated in medium at $60^{\circ} \mathrm{C}$ for 3 hours or 1,4 , or 7 days. (B) Crumb rubber incubated in medium at $37^{\circ} \mathrm{C}$ for 3 hours or 1,4 , or 7 days. (C) Crumb rubber incubated in medium at ambient temperature for 3 hours or 1, 4, or 7 days. Statistics are shown on graphs only for decreased Ab 490 nm vs. 0 (cytotoxicity) (two-way ANOVA; * $=p<0.05$ vs. 0). 

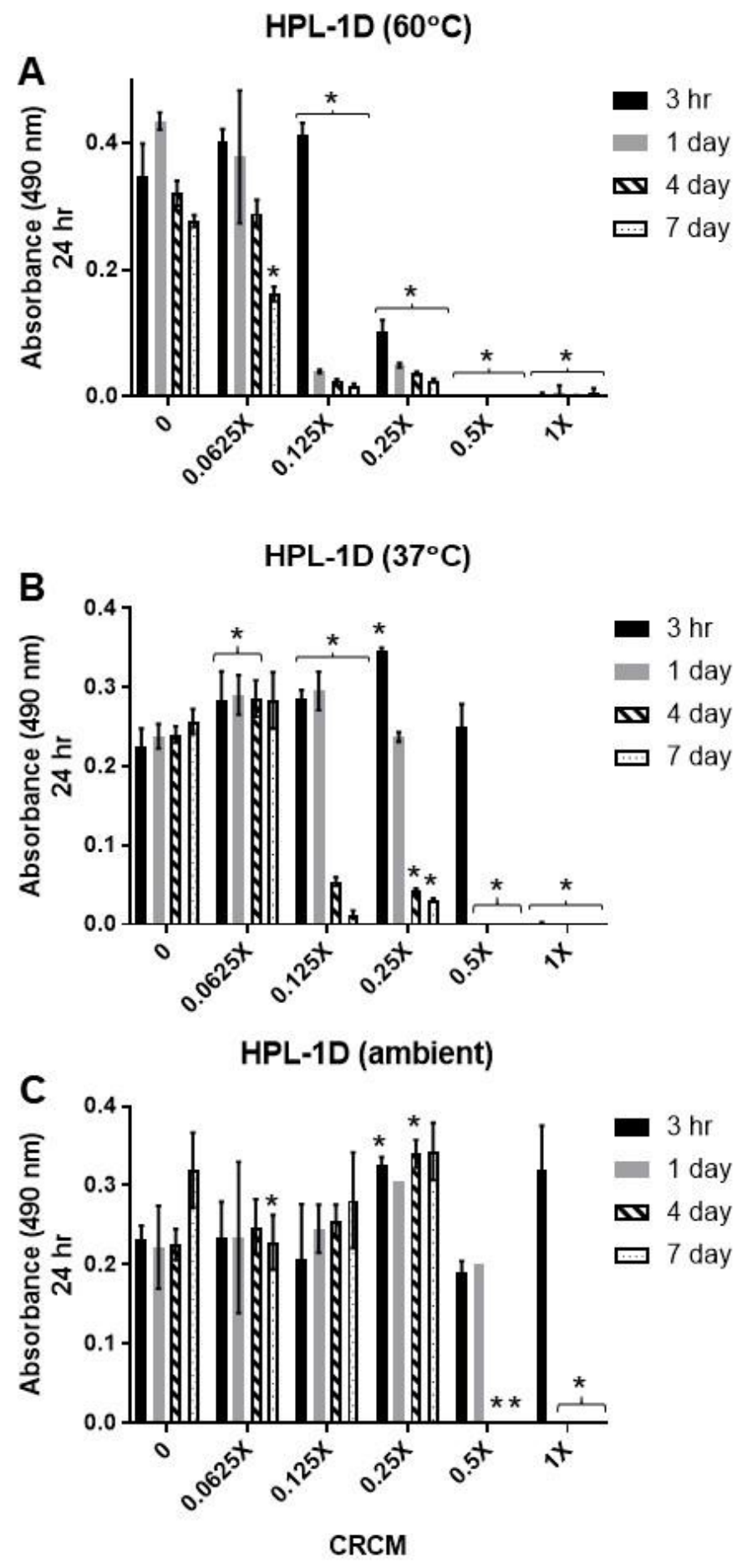

Figure 2. CRCM Is Cytotoxic to HPL-1D Lung Cells

HPL-1D cells were exposed to crumb rubber-conditioned medium (CRCM) $(1,0.5,0.25,0.125$, or $0.0625 \mathrm{X})$ or control $(0 \mathrm{mg} / \mathrm{mL}$ crumb rubber) medium for 24 hours, as described in Materials and Methods. Cell viability (Ab $490 \mathrm{~nm}$ ) was measured using an MTS assay. Mean \pm SD $(n=3)$ values are shown on graphs (for a single representative experiment). (A) Crumb rubber incubated in medium at $60^{\circ} \mathrm{C}$ for 3 hours or 1,4 , or 7 days. (B) Crumb rubber incubated in medium at $37^{\circ} \mathrm{C}$ for 3 hours or 1,4 , or 7 days. (C) Crumb rubber incubated in medium at ambient temperature for 3 hours or 1, 4, or 7 days. Statistics are shown on graphs only for decreased Ab $490 \mathrm{~nm}$ vs. 0 (cytotoxicity) (two-way ANOVA; * $=\mathrm{p}<0.05$ vs. 0 ). 
Synthetic Turf/Recycled Tire Crumb Rubber:

Characterization of the Biological Activity of Crumb Rubber In Vitro

\section{HPL-1D}
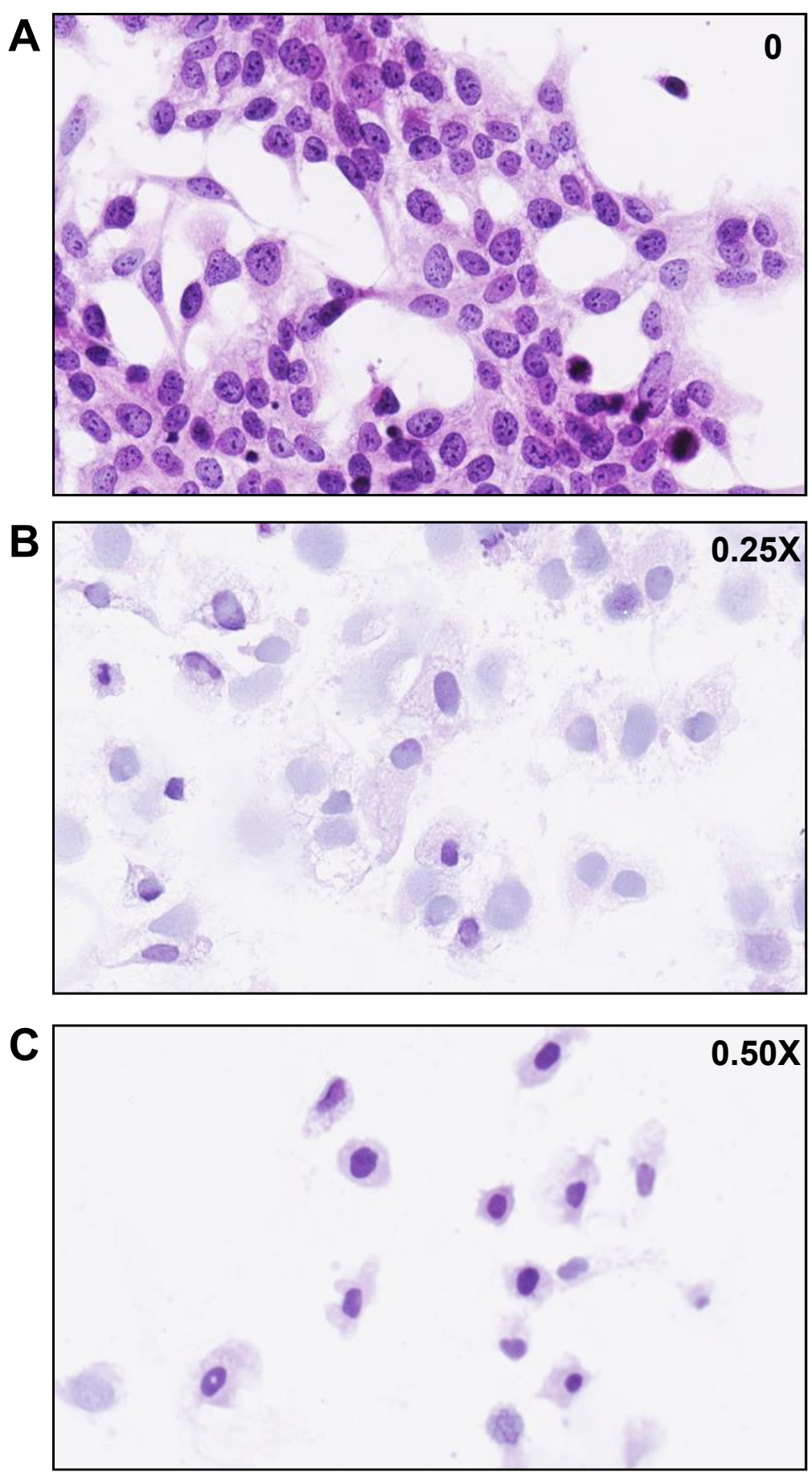

Figure 3. Histologic Evaluation of HPL-1D Lung Cells Exposed to CRCM

Crumb rubber was incubated in culture medium at $60^{\circ} \mathrm{C}$ for 1 day. HPL-1D cells were exposed to crumb rubber-conditioned medium (CRCM) $(0.5$ or $0.25 \mathrm{X})$ or control $(0 \mathrm{mg} / \mathrm{mL}$ crumb rubber) medium for 24 hours using 8 -well chamber slides and then H\&E stained, as described in Materials and Methods. HPL-1D cells exposed to (A) 0 (control medium), (B) 0.25X CRCM, or (C) $0.5 \mathrm{X}$ CRCM are shown (40X magnification). 

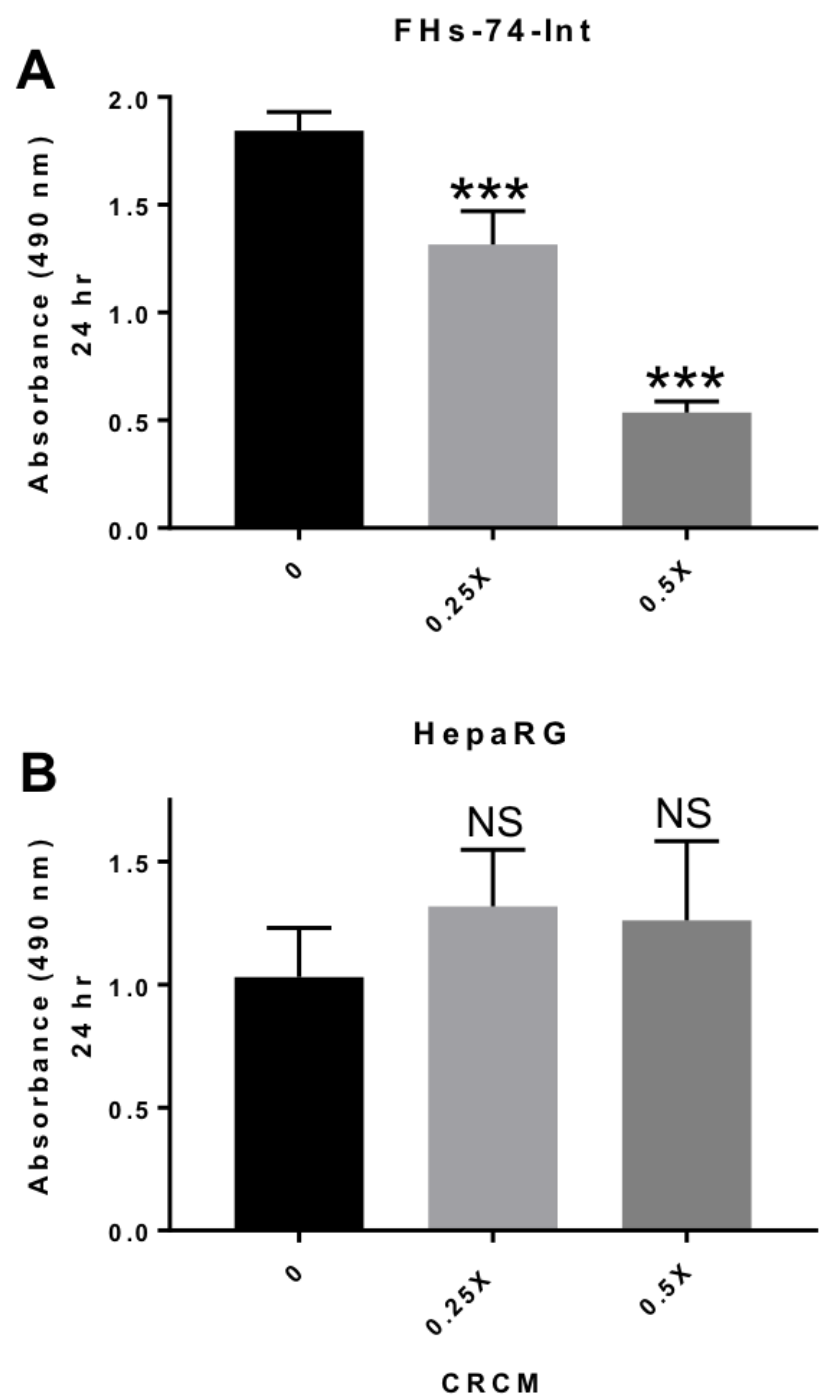

Figure 4. CRCM Is Cytotoxic to FHs-74-Int Small Intestinal Cells but Not to HepaRG Cells

Crumb rubber was incubated in culture medium at $60^{\circ} \mathrm{C}$ for 1 day. FHs-74-Int or HepaRG cells were exposed to crumb rubberconditioned medium (CRCM) $(0.5$ or $0.25 \mathrm{X})$ or control $(0 \mathrm{mg} / \mathrm{mL}$ crumb rubber) medium for 24 hours, as described in Materials and Methods. Cell viability (Ab $490 \mathrm{~nm})$ was measured using an MTS assay. Mean \pm SD $(\mathrm{n}=8-9)$ values are shown on graphs. (A) FHs-74-Int cells (one-way ANOVA; $* * *=p<0.001$ vs. 0). (B) HepaRG cells (one-way ANOVA; not significant [NS] vs. 0). 
H PL -1D

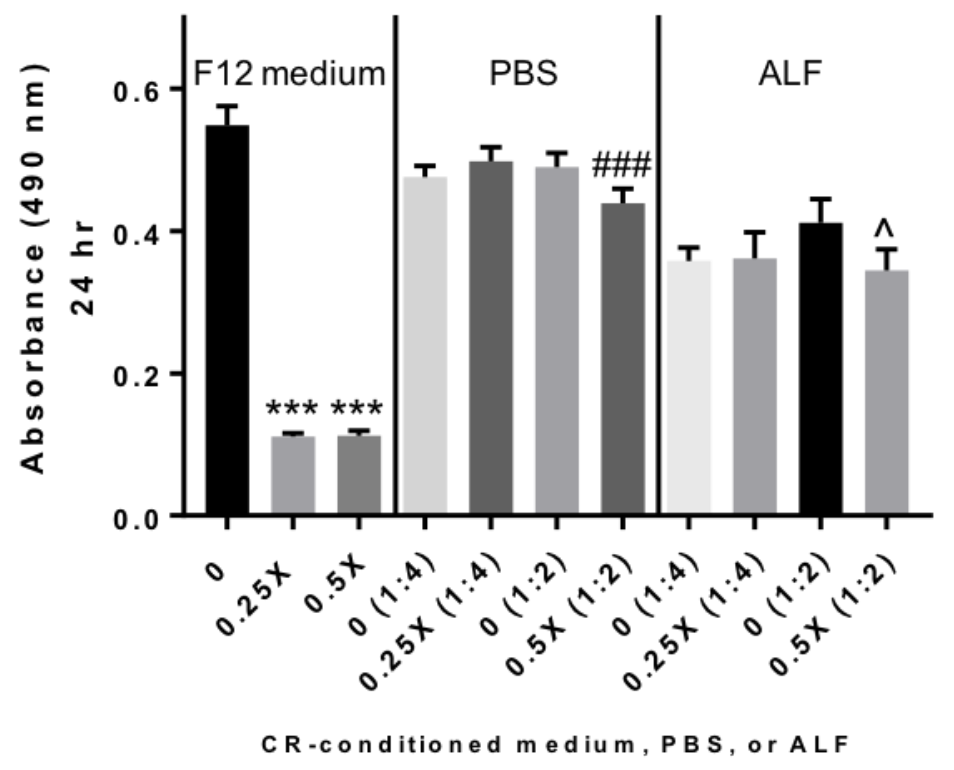

Figure 5. Crumb Rubber-conditioned PBS and ALF Are Not Cytotoxic to HPL-1D Lung Cells

Crumb rubber (CR) was incubated in HPL-1D culture medium (F12 medium), phosphate-buffered saline (PBS), or artificial lung fluid (ALF) at $60^{\circ} \mathrm{C}$ for 1 day. HPL-1D cells were exposed to CR-conditioned medium $(0.5$ or $0.25 \mathrm{X})$ or control $(0 \mathrm{mg} / \mathrm{mL}$ crumb rubber) medium; CR-conditioned PBS in culture medium $(0.5$ or $0.25 \mathrm{X})$ or control $(0 \mathrm{mg} / \mathrm{mL}$ crumb rubber) PBS (1:2 or $1: 4$ dilution-matched in culture medium); or CR-conditioned ALF in culture medium $(0.5$ or $0.25 \mathrm{X})$ or control $(0 \mathrm{mg} / \mathrm{mL} \mathrm{crumb}$ rubber) ALF (1:2 or 1:4 dilution-matched in culture medium) for 24 hours, as described in Materials and Methods. Cell viability $(\mathrm{Ab} 490 \mathrm{~nm}$ ) was measured using an MTS assay. Mean \pm SD values $(\mathrm{n}=12$ for $0, \mathrm{n}=6$ for all other treatment groups) are shown on graph (one-way ANOVA; $* * *=p<0.001$ vs. 0 for medium group and vs. 0.5 and $0.25 X$ for PBS and ALF groups, $\# \# \#=\mathrm{p}<0.001$ vs. 0 [1:2] for PBS group, ${ }^{\wedge}=\mathrm{p}<0.05$ vs. 0 [1:2] for ALF group). 
Synthetic Turf/Recycled Tire Crumb Rubber:

Characterization of the Biological Activity of Crumb Rubber In Vitro

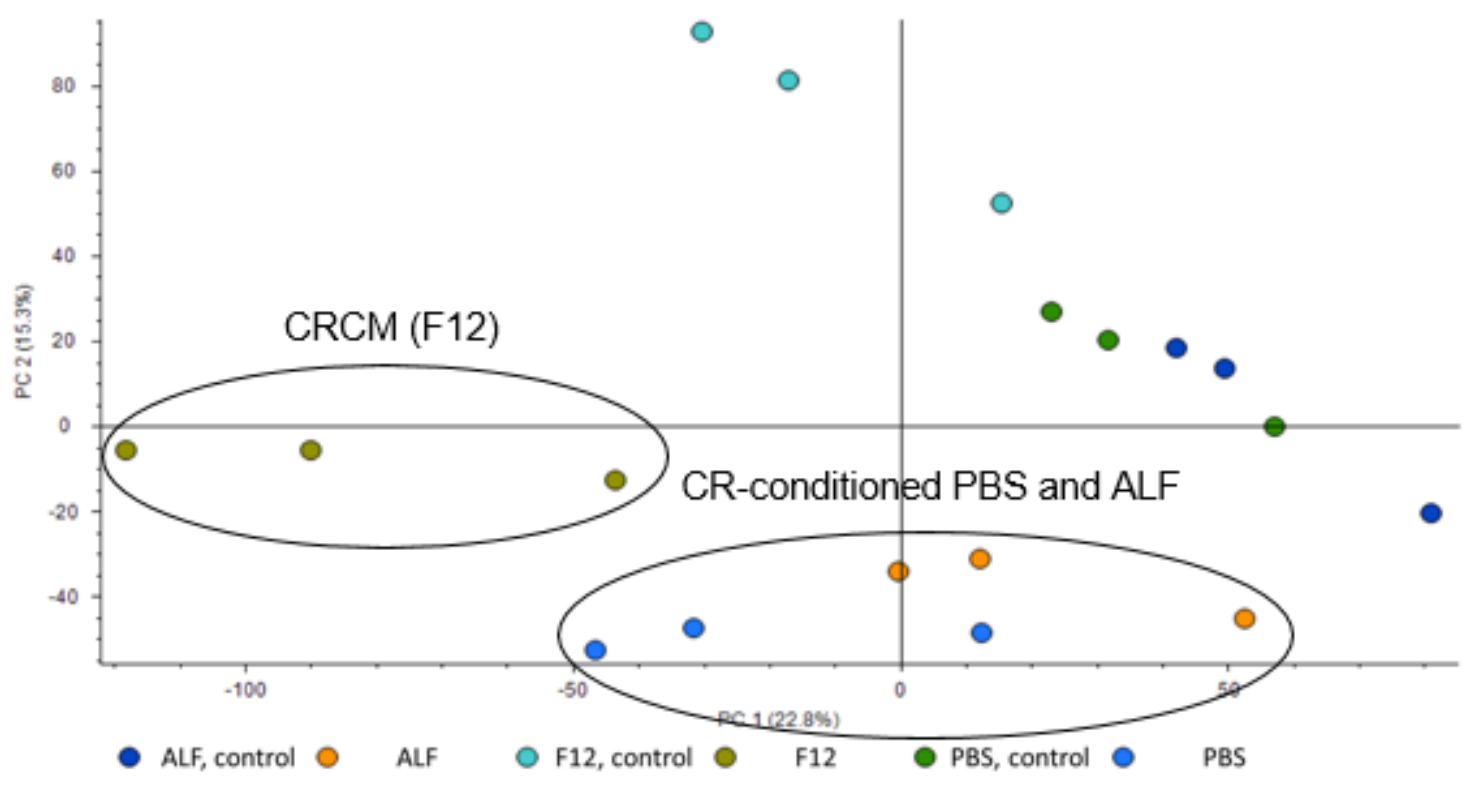

Figure 6. UPLC-MS Analysis of CRCM and Crumb Rubber-conditioned PBS or ALF

Crumb rubber (CR) was incubated in HPL-1D culture medium (F12), phosphate-buffered saline (PBS), or artificial lung fluid (ALF) at $60^{\circ} \mathrm{C}$ for 1 day. CR-conditioned medium (CRCM) (F12), CR-conditioned PBS (PBS), CR-conditioned ALF (ALF), or respective controls (F12, control; PBS, control; ALF, control) were analyzed in triplicate by non-targeted UPLC-MS. A PCA (PC1 and PC2) plot is shown. Circles indicate distinct groupings of CRCM (F12) or CR-conditioned PBS and ALF. 


\section{HPL-1D $\left(60^{\circ} \mathrm{C}\right)$}

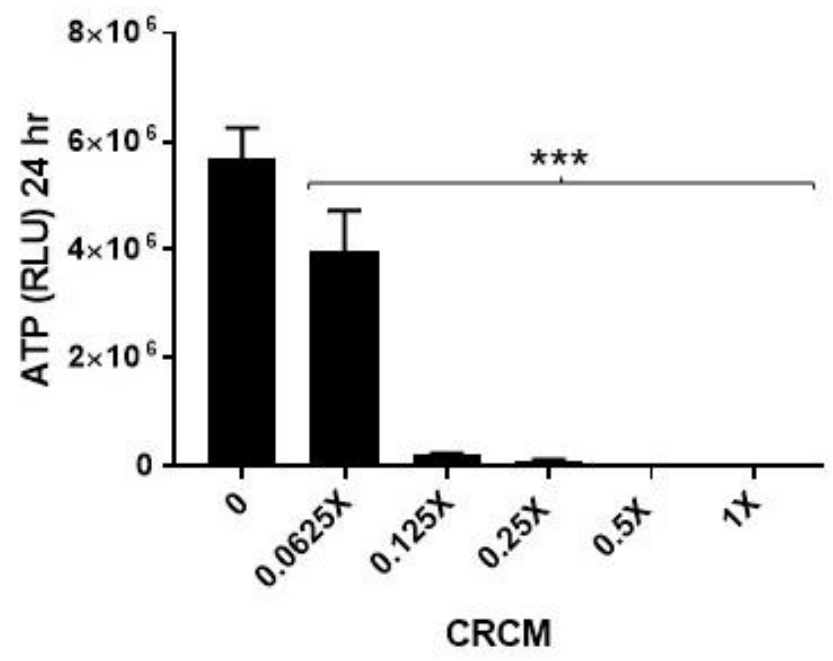

Figure 7. CRCM Is Cytotoxic to HPL-1D Lung Cells Using CTG Assay

Crumb rubber was incubated in culture medium at $60^{\circ} \mathrm{C}$ for 1 day. HPL-1D cells were exposed to crumb rubber-conditioned medium (CRCM) $(1,0.5,0.25,0.125$, or $0.0625 \mathrm{X})$ or control $(0 \mathrm{mg} / \mathrm{mL}$ crumb rubber $)$ medium for 24 hours, as described in Materials and Methods. The CTG assay was used to measure ATP levels (RLU) to determine cell viability. Mean \pm SD $(n=5)$ values are shown on graph (one-way ANOVA; $* * *=p<0.001$ vs. 0 ). 


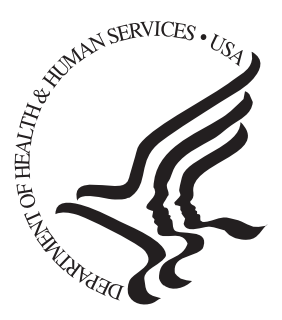

\section{National Toxicology Program}

NTP Central Data Managment, MD K2-05

National Insitute of Enviromental Health Sciences

P.O. Box 12233

Research Triangle Park, NC 27709

http://ntp.niehs.nih.gov 